\title{
An Assessment of the Implementation of the National Policy on Local Economic Development by District Assemblies in Ghana
}

\author{
Kwasi Larnyoh \\ Department of Local and Regional Economic Development, Institute of Local Government Studies, Accra, Ghana \\ Email address: \\ kklarnyoh@yahoo.co.uk \\ To cite this article: \\ Kwasi Larnyoh. An Assessment of the Implementation of the National Policy on Local Economic Development by District Assemblies in \\ Ghana. Journal of Business and Economic Development. Vol. 4, No. 1, 2019, pp. 1-10. doi: 10.11648/j.jbed.20190401.11
}

Received: December 14, 2018; Accepted: January 20, 2018; Published: January 31, 2019

\begin{abstract}
Policies are important inputs to the economic development process of any territory. But policies, of themselves, cannot bring about the desired goals unless they are duly implemented. In Ghana, experience has shown that many good policies formulated in the past did not get implemented. Also, the pace of implementation of many other policies has been terribly slow resulting in huge time lag between policy formulation and implementation. This study thus investigated the extent of implementation of the National LED Policy formulated in 2013 and made operational from January 2014. The study is a case study survey of two District Assemblies: Asuogyaman and Ada West District Assemblies. These Assemblies were purposively selected based on the endowment of some natural resources. The broad objective was to find out whether District Assemblies are delivering on their roles and responsibilities as provided by the National LED Policy. The study found that the District Assemblies studied have not put in much effort specifically aimed at implementing the National LED Policy in their jurisdictions.
\end{abstract}

Keywords: Ghana, Local Economic Development Policy, Ada West, Asuogyaman, District Assemblies

\section{Introduction}

\subsection{Background}

Ghana has in the recent past made significant efforts at reducing poverty levels and improving the lives of its citizens. These efforts seem inadequate as issues such as high levels of poverty, unemployment, and hunger among others still abound. Addressing these phenomena requires a paradigm shift in the approach to development planning.

Local Economic Development (LED) has recently emerged as a vital strategy for promoting job creation and reducing poverty particularly in the context of global trends towards decentralisation and of shifting structures of governments and governance [1]. Since its emergence, LED has been embraced as the new global order for planning effective development at the local level linked to national level policies. It is a bottom up approach to economic growth through the realization and utilisation of the economic potentials of every territory. Indeed, Bartik [2] defines LED as "increases in the "local economy's capacity to create wealth for local residents". LED strategies bring together different partners in a local area to work together and harness local resources for sustainable economic growth [3]. According to Blakely and Bradshaw [4], the principal goal of LED is to stimulate local employment opportunities in sectors that improve the locality using existing human, natural and institutional resources.

Policies are mechanisms employed to realise societal goals and to allocate resources [5]. They are important inputs to the economic development process of any territory. The broad objective of any LED policy is to facilitate economic growth, employment and income generation in order to promote household livelihoods and alleviate poverty. But policies, of themselves, cannot bring about the desired goals unless they are duly implemented; that is, the policy decisions carried out. In Ghana, experience has shown that many good policies formulated in the past did not get implemented. For instance, a Rural Development Policy was prepared in the 1980s to facilitate and accelerate development of the rural areas in 
Ghana. This was a good policy given the scope of rural settlements in Ghana. However, the policy remains a draft and unimplemented. Also, the pace of implementation of many other policies has been terribly slow resulting in huge time lag between policy formulation and implementation. For instance, after many years of implementation of decentralisation the policy on fiscal decentralization is yet to take full shape at the local level. District Assemblies still look up to the central state level for financial resource allocation. Departments located at District Assemblies still continue to report and look up to their parent ministries, or regional offices for direction despite many years of the passage of the L.I. 1961 requiring such departments to be transferred to the District Assemblies.

There is an increasing recognition that the quest to achieve national development goals could only happen when the goals are translated into actions at the sub-national levels and by active involvement of local actors. This in turn has brought about renewed attention to planning for local economic development, which is output and impact oriented and linked to the national level policies and budget processes [6]. Hence the role of local governments in preparing, coordinating and implementing local development strategies cannot be overemphasized. Section 10(3) of the Local Government Act of Ghana, 1993 Act 462 duly recognises District Assemblies as being "responsible for the overall development of the district" [7]. Thus it beholds on District Assemblies to make every effort to implement policies aimed at bringing developments to their territories. This paper attempts to ascertain whether district assemblies in Ghana are practically implementing the National Policy on Local Economic Development.

\subsection{Statement of Problem}

LED has been recognised as the new global order for planning effective development at the local level linked to national level policies. The broad objective of any LED policy is to facilitate economic growth, employment and income generation in order to promote household livelihoods and alleviate poverty. But policies, of themselves, cannot bring about the desired goals unless they are duly implemented. The Local Government Act vests District Assemblies with the responsibility for the overall development of their districts. Provisions in the Act provide a framework for the assemblies to focus on using local resources for local development. Experience has however shown that many good policies formulated in the past did not get implemented. The Government of Ghana, in the year 2013 formulated a national LED policy whose introduction is seen as an alternative development strategy to fully harness the economic potentials of District Assemblies for job creation and improved living standards. The broad objective of the policy is to build up the economic capacity of a local area to improve its economic status and the quality of life of for all. The overall goal of the policy is to facilitate economic growth, employment and income generation in order to promote household welfare and alleviate poverty. However, efforts to effectively implement the key activities of the policy by District Assemblies so as to bring about the desired goals are largely unknown. Studies in Ghana on decentralization and LED rarely focus on the efforts made by District Assemblies to implement LED policies [6]. This creates a gap in knowledge regarding the efforts by District Assemblies at implementing LED policies. This study seeks to fill this gap by finding out the steps being taken by District Assemblies to implement the National LED Policy.

\subsection{Objectives of the Study}

The broad objective of this study is to find out whether District Assemblies are delivering on the roles and responsibilities expected of them in the National LED Policy. The specific objectives are to:

a). explore the resources and opportunities available for LED interventions in the Districts

b). find out the activities the district assemblies have undertaken to mainstream LED into their district development plans

c). explore the specific interventions being put in place by District Assemblies to implement the National LED policy in their jurisdictions

d). find out the challenges facing District Assemblies in the implementation of the National LED policy.

\subsection{Research Questions}

a). What are the resources and opportunities available for LED interventions in the Districts?

b). What activities have the districts assemblies undertaken to mainstream LED into their district development plans?

c). What interventions are being put in place by District Assemblies to implement the National LED policy?

d). What challenges are District Assemblies facing in the implementation of the National LED policy?

\subsection{Significance of the Study}

The Local Government Act 1993, Act 462 enjoins Metropolitan, Municipal and District Assemblies (District Assemblies) in Ghana to mobilise local level resources for the overall development of their districts [7]. In recognition of this, the National LED policy formulated in 2013, assigned some roles and responsibilities to District Assemblies to enable them implement the policy in their respective jurisdictions. Experience has however, shown that many good policies formulated in the past have not been implemented. Is this policy also going to suffer the same fate? This study therefore aims at finding out the initiatives taken by District Assemblies towards implementation of the national LED policy. It will reveal whether or not District Assemblies are taking significant steps towards the implementation of the policy. Challenges faced by District Assemblies in this regard will also be brought to the fore. The results will provide useful information to the makers of the policy as well as District Assemblies on the state of implementation and the challenges thereof. In addition, it will 
contribute to the literature on policy implementation.

\subsection{Review of Relevant Literature}

\subsubsection{Local Economic Development: Meaning and Rationale}

The term "local economic development" has numerous meanings in literature. The World Bank considers that the activity of LED is concerned with "local people working together to achieve sustainable economic growth that brings economic benefits and quality of life improvements for all in the community" [8]. According to Blakely and Bradshaw (2002) [4], LED refers to "the process in which local governments or community-based organizations engage to stimulate or maintain business activity and /or employment. The principal goal of local economic development is to stimulate local employment opportunities in sectors that improve the community using the existing human, natural, and institutional resources". To Bartik (2003), it means increases in the "local economy's capacity to create wealth for local residents" [2]. Such increases, according to Bartik, occur if local resources, such as labour and land, are used more productively. Helmsing and Egziabher (2005) consider LED to be "a process in which partnerships between local governments, NGOs, community-based groups and the private sector are established to manage existing resources, to create jobs and stimulate the economy of a well-defined territory" [9]. The ILO (2006) defines LED as a "participatory development process that encourages partnership arrangements between the main private and public stakeholders of a defined territory, enabling the joint design and implementation of a common development strategy, by making use of the local resources and competitive advantage in a global context, with the final objective of creating decent jobs and stimulating economic activities" [10]. LED is also defined as the structural and growth process which, by making full use of local resources, leads to a continuous increase of the welfare of the people living in a local area [11]. Also, according to Koma (2014), LED is a process which brings together different partners in a local area to work together and harness local resources for sustainable economic growth. These definitions, either explicitly or by implication indicate that LED:

a). is a territorial approach to development

b). has preference for integrated and participatory strategies

c). focuses on the creation of sustainable and decent work

d). creates incentives and opportunities for partnerships

e). enables joint formulation and implementation of development strategies [12].

Traditional approaches to development had mainly been a top-down approach where development policies were formulated and implemented at the national level. This has proven ineffective in tackling developmental challenges in the targeted localities [13]. Poverty and underdevelopment still persist in many countries around the world. The failure of the traditional top-down approach to development called for a re-thinking and re-fashioning of development strategies
[14]. The emergence of LED as an alternative development strategy can thus be seen as a response to the failure of topdown development programs in promoting economic development on the local level. The rationale for adopting any LED strategy is to improve on living conditions of the people of any locality through the creation of jobs and stimulating economic activities within the locality. LED stimulates citizens of a locality towards participating in enterprise creation. It guarantees suitable conditions for sustainable jobs. As Catenacci (2003) puts it, "LED combats the traditional model of economic development that gives the task and privilege of producing wealth to a small segment of the population and relies on the unlikely trickle-down effect to get to the poor" [15]. The LED objective is achieved through a collaborated effort of local stakeholders often with support from external bodies such as central government and development partners.

\subsubsection{Theoretical Underpinning of LED}

LED is still an emerging field. As such, currently, no single theory or sets of theories adequately explains it, but several partial theories point to an underlying rationale [4]. Mainly, two broad classes of theories help us understand the process of LED: location theories, which focus on geographical factors, and economic base theories, which focus on the flow of economic activity into and out of the local economy. However, the economic-base theory dominates the thinking about LED. Andrews, as cited in Tello (2010), defines "economic base" as the set of activities in a "region" (defined as a local geographic area) which exports goods and services to points outside its economic boundaries, or sells its goods and services to outsiders [11]. The theory postulates that the region's economic growth is driven by growth in the export activities of the economic base. Distinguishing between base (export oriented) and non-base (regional consumption oriented) economic activities, the economic base theory assumes that a region's economic well-being depends on the health of its base sector. This sector comprises of local businesses that are dependent upon external markets. The theory focuses exclusively on external demand as the determinant of the growth of a locality. Internal demand and supply are viewed as relatively insignificant sources of income and employment growth. The LED literature indicates that, there are various mechanisms through which the agglomeration of economic base and non-base activities generates economic growth and development for the locality concerned through the income/employment multiplier mechanism whereby a higher income and employment in the economic base activities will increase the demand for goods and labour in the non-base activities. Thus, every job created in an export firm will generate several jobs elsewhere in the economy. A second mechanism also operates through the backward and forward inter-sectoral linkages generated by the economic base activities when there are idle resources in the region/locality [11]. Generally, the economic base theory relies heavily on a sectoral approach to economic development which concentrates on transactions within the 
economic system rather than the failures and inadequacies of the system in which the transactions are taking place.

The logical conclusion to the economic base theory is that the key to a locality's development lies in its ability to attract and retain a core of businesses that generate exportable goods and services.

\subsubsection{Legislative and Policy Contexts for LED in Ghana}

The role of District Assemblies in promoting LED in Ghana are clearly defined by the Fourth Republican Constitution and other Acts of Parliament and policies. The 1992 constitution [16] places a great responsibility on District Assemblies to facilitate LED. It mandates District Assemblies to play a key role in creating a conducive environment for investment through the provision of infrastructure and quality services. Also, the Local Government Act of 1993, Act 462 establishes the District Assemblies as planning authorities at the local level with the legal mandate to formulate and execute plans, programmes and strategies for effective resource mobilisation for the overall development of the district [7]. Act 462 therefore provides District Assemblies with powers and functions to ensure competitiveness and growth of the local economy for economic opportunities for citizens. National Development Policy Frameworks such as the Ghana Shared Growth and Development Agenda (GSGDA) recognise that District Assemblies must have the requisite capacities to fulfil their obligations effectively to promote local development. District Assemblies are therefore mandated to determine and implement comprehensive bespoke policies, programmes and activities in accordance with their own social and economic conditions. LED is one of the key priority areas under the thematic area "Private Sector Development" in the District Assemblies Medium Term Development Plan.

Other related legislations and policy frameworks for decentralisation and LED in Ghana include:

a).National Decentralisation Policy Framework

b).Urban Development Policy

c). National Industrialisation Policy

d). Intergovernmental Fiscal Framework

e). National Development Planning System Act, 1994, Act 480

f). District Assemblies Common Fund Act, 1993, Act 455

g). Local Government Service Act, 2003, Act 656

h). Institute of Local Government Studies Act, 2003, Act 647

i). Legislative Instrument 1589

j). Legislative Instrument 1961

\subsubsection{Overview of the National LED Policy}

Decentralisation under the 1992 constitution of Ghana designates District Assemblies as the highest political authority in the district with deliberative, legislative and executive powers. Also the local government Act, 1993 Act 462 vests District Assemblies with administrative, planning and budgeting authority at the local level with the responsibility for overall development of their districts. District Assemblies have so far, focused on their administrative and legislative functions to the detriment of their LED functions thereby hindering their efforts to improve quality of life and to offer greater opportunities for economic empowerment of their citizens [17]. Poverty reduction, which has been the aims of many centralised development strategies, has not been realised. It is in this respect that that the National LED Policy was developed to help reduce poverty through increased economic growth and inclusion. The overall policy goal is to facilitate economic growth, employment and income generation in order to promote household welfare and alleviate poverty. The policy seeks to address the following objectives:

a). Improve institutional arrangements and legislative framework for LED;

b). Strengthen local economic competitiveness and LED governance;

c). Promote LED initiatives with emphasis on innovation and human development;

d). Provide urban and rural infrastructure to enhance quality service at the local level;

e). Identify and harness existing and potential, human and financial resources;

f). Enhance the capacity of local economic actors and LED institutions;

g). Build capacity of RCCs and District Assemblies to monitor environmental impacts of LED activities;

h). Enable local governments to support local economies to realise their potentials and make local communities active participants in the economic activities

i). Empower local governments to facilitate functioning partnerships between the public and private sectors in order to unlock the local economy and drive new growth;

j). Provide a financing framework to coordinate funding flows in support of the strategy; and

k). Promote broad based local participation in the economy.

The policy adopts the definition of LED as provided by Ghana's National Decentralisation Policy, which defines LED as the process by which local governments, local businesses and other actors join forces and resources to enter into new partnership arrangements with each other or other stakeholders to create new jobs and stimulate economic activities in municipalities, and villages [18]. This definition recognises that LED is a process and it is driven by local actors.

The roles and responsibilities of District Assemblies spelt out in the National LED Policy include:

a). Mainstreaming LED into Medium Term Development Plans

b). Identifying local level resources and opportunities

c). Ensuring that the overall economic and social conditions of the locality are conducive to the creation of employment opportunities

d). Providing infrastructural support to facilitate LED

e). Facilitating participatory decision making and partnership building with non-state actors in the direction of LED. 
A five-year Action Plan (2014 - 2018) for national and District Assemblies has been developed to facilitate the operationalisation of the policy.

\subsubsection{The LED Implementation Process}

An operational manual on LED was developed by the Ministry of Local Government and Rural Development to help District Assemblies in the implementation of the National Led Policy in their respective jurisdictions. The manual gives a stepby-step guide (though not a straight-jacket formula) to initiate and implement LED. The steps are briefly described below.

\section{i. Step 1: Pre-Initiation Stage}

Here the district assembly is expected to mobilise resources for the commencement of the LED implementation process. The assembly is expected to identify key stakeholders and plan for stakeholder engagements; presentation on the LED concept; brainstorming sessions to identify LED priorities; assigning roles and responsibilities; and buy-in and ownership of the LED process. By the end of this, the assembly should be able to come up with a work-plan for LED.

\section{ii. Step 2: Initiation Stage}

At this stage, the District Assembly is expected to provide strategic leadership for LED programmes within its jurisdiction. The other stakeholders should be made to play their roles to ensure ownership and sustainability of the process. A key feature here is the composition of an Economic Development Committee (EDC). Membership of the EDC is drawn from the DPCU, Assembly Members, Private Sector and Civil Society. Among other things, functions of the EDC include: coordinate the implementation of identified tasks by responsible departments or agencies; ensure capacity development of all stakeholders; mobilise resources to support LED; develop and implement appropriate communication strategy; collate documentation on LED work; and undertake joint monitoring and evaluation activities.

iii. Step 3: Diagnostic Analysis Stage

Here, the EDC is expected to assess and acquire knowledge about the local economy and the resources available for economic and social development. The EDC can employ tools such as economic survey, SWOT analysis in this endeavour and produce a diagnostic report.

\section{iv. Step 4: LED Stakeholder Dialogue}

At this stage the EDC is expected to set up and institutionalise LED Platforms to execute its functions as prescribed in the LED policy. The LED platform may be composed to include: local financial institutions, private sector, civil society and traditional authorities. The functioning LED platform should be able to come up with an LED Composite Programme of Action and LED Annual Action Plan as inputs into the district's MTDP and for the other platform stakeholder groups and institutions.

\section{v. Step 5: Implementation of LED Action Plan}

Here, the District Assembly is expected to mainstream the LED Composite Programme of Action and the LED Annual Action Plan into the MTDP as well as the strategic plans of the other LED platform stakeholders. All stakeholders, at this stage, are expected to collaborate to implement the LED Action Plan and MTDP.

\section{vi. Step 6: Resource Mobilisation}

At step 6, the District Assembly is expected to identify, discuss and mobilise both internal and external resources for the implementation of LED related activities in the MTDPs and the Strategic Plans of the other LED platform stakeholders.

vii. Step 7: Participatory Monitoring and Evaluation

Here, the District EDC and other LED platform stakeholders should collect, compile, analyse and disseminate relevant and timely disaggregated data on LED.

\subsubsection{The Study Districts}

The study was undertaken in the Asuogyaman and Ada West District Assemblies.

\section{i. Ada West District}

The Ada West District was carved out of the former Dangbe East District in the Greater Accra Region. It was established in 2012 by Legislative Instrument (LI. 2029) with its capital at Sege. The District shares boundaries with North Tongu District to the North, Ada East District and Ningo Prampram to the East and West respectively. It is bounded to the South by the Gulf of Guinea which stretches from Akplabanya to Goi. It is approximately 80 Kilometers from Accra, the regional capital. The total land size of the district is about 323.721 square kilometres. Figure 1is a map of the Ada West District.

The natural environment of the district to a large extent dictates the economic activities that go on there. Salt mining provides employment for a large number of the population particularly in areas where the resource exists. The District mostly gains its revenue from the commodity. The district is however predominantly an agricultural one making farming a major economic activity. Apart from the natural environment a contributory factor to this is due to the fact that the majority of the population lives in rural settlements. Crops farmed are mainly cassava, maize and among others. Vegetables like tomatoes, onions, shallots, garden eggs, pepper, carrots, and okra. Fruits such as water melon also feature predominantly to sustain the livelihood of farmers (Ghana Statistical Service, 2010).

\section{ii. Asuogyaman District}

The Asuogyaman District is located approximately between latitudes $6^{\circ} 34^{\circ} \mathrm{N}$ and $6^{\circ} 10^{\circ} \mathrm{N}$ and longitudes $0^{\circ} 1^{\circ}$ $\mathrm{W}$ and $0^{\circ} 14^{\circ} \mathrm{E}$. It covers a total estimated surface area of 1,507 sq. km. The Administrative capital of the District is Atimpoku. The Asuogyaman District Assembly (ADA) is the highest political authority in the district. The District has been divided into six Area Councils in line with the provisions of the Local Government Act, 467(1993). They are Anum, Boso, Frankadua/Apeguso, Atimpoku, Gyakiti and Akosombo.

Majority of the people in the district are engaged in agriculture and related trades. There are three (3) prominent types of agricultural activities in the district. These are livestock rearing, food cropping and cash cropping. However, most of the farming activities in the district are focused on the production of food crops. Figure 2 is a map of the Asuogyaman District. 


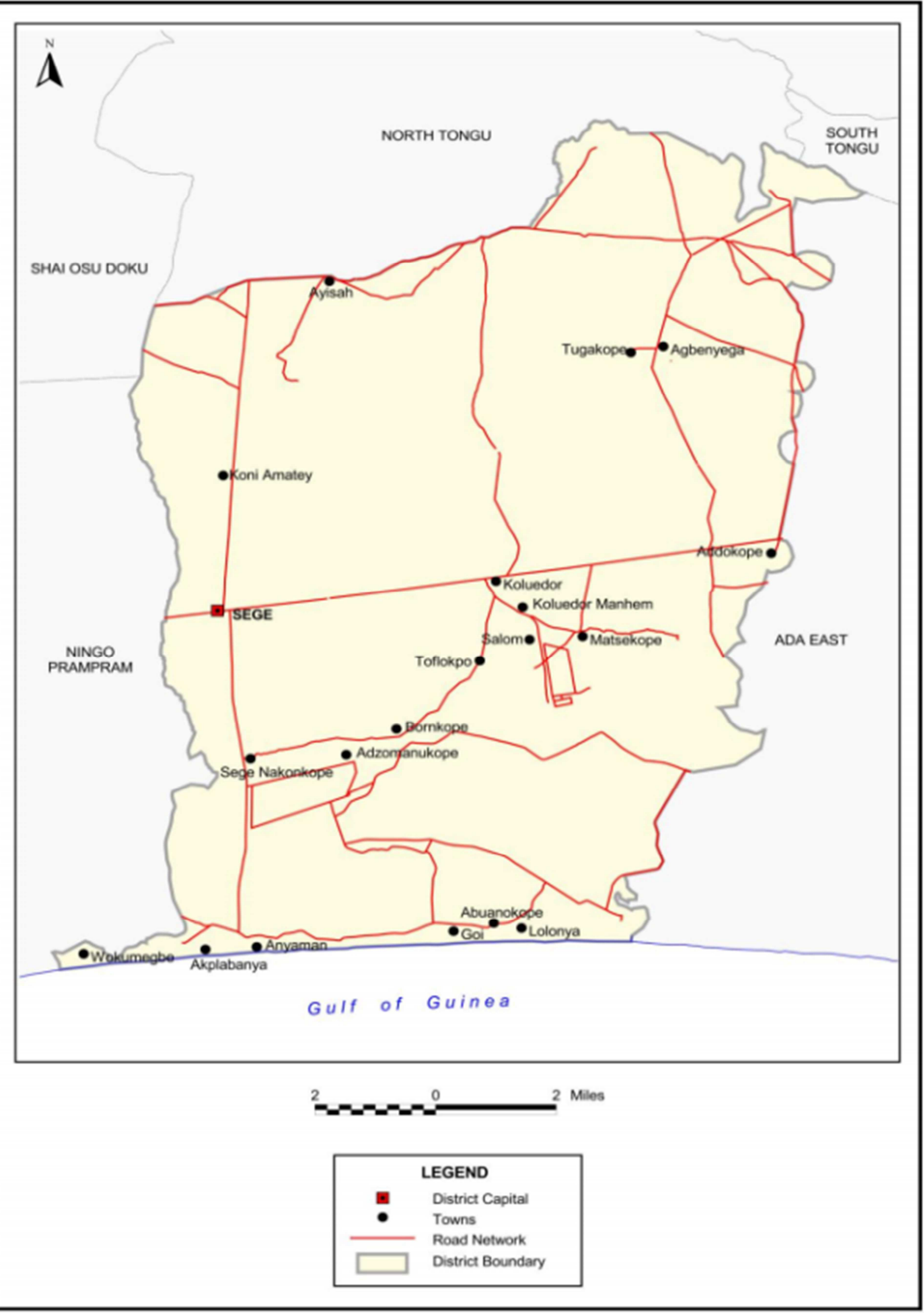

Source: Ghana Statistical Service, 2010

Figure 1. Map of Ada West District. 


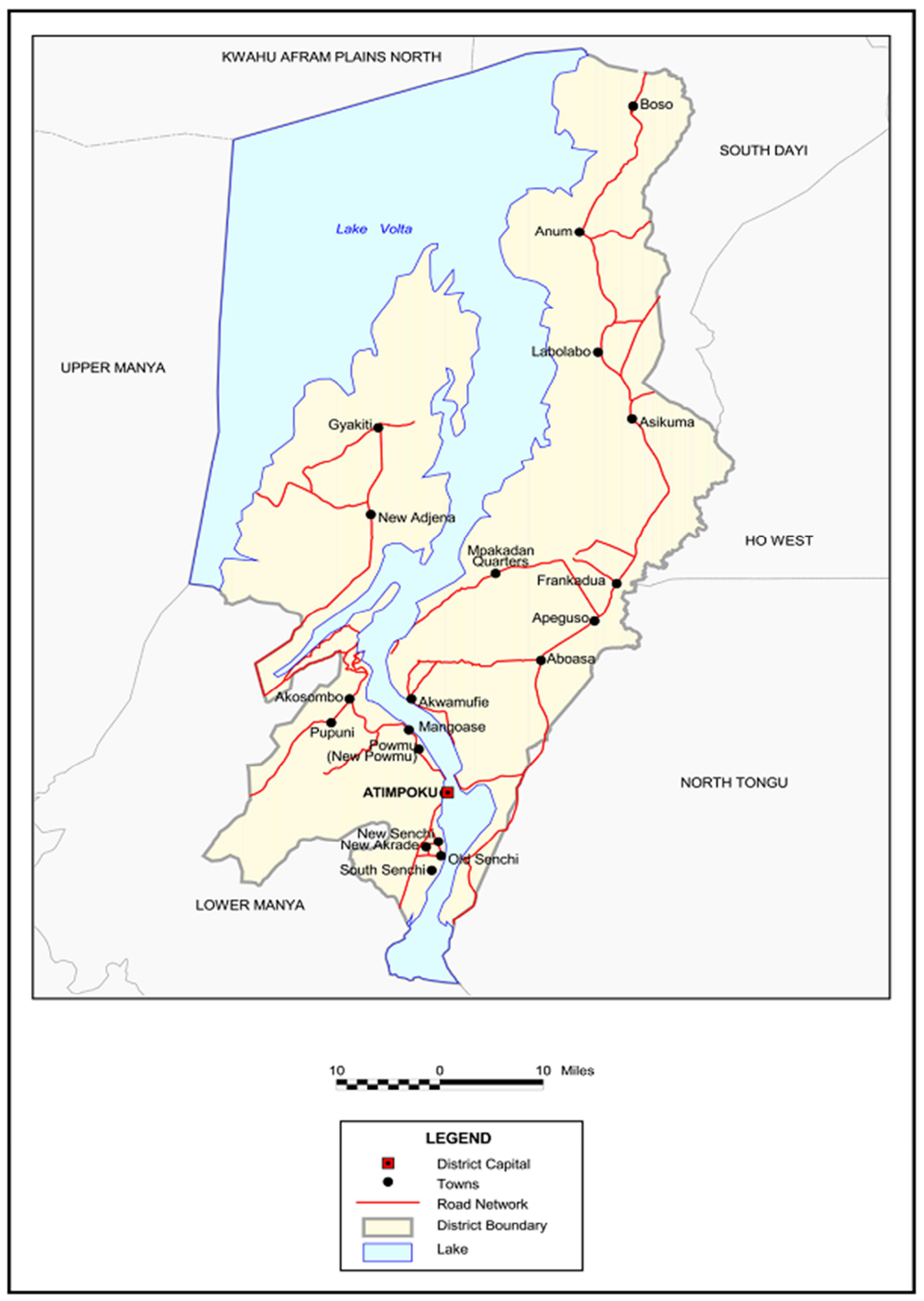

Source: Ghana Statistical Service, 2010.

Figure 2. Map of Asuogyaman District.

Fishing in the Volta Lake also constitutes an important segment of the agriculture sector. Fishing is done mainly in some communities along the $141 \mathrm{~km}$ shoreline including parts of the Kpong headwaters. These communities include Dzidzokope, Atimpoku, Abume, Akosombo, Surveyline,
Adomi, Dodi Asantekrom, Asikuma, Mpakadan and Senchi and old Akrade.

Volta River Authority and Akosombo Textiles form the major industry employing a major proportion of the population. Major hotels and tourist sites (Volta Hotel, 
Senchi Royal Hotel, Akosombo Continental Hotel, Afrikiko River Front and Sajuna Beach Park) also contribute to.The economy by attracting tourists from all parts of the world. Atimpoku is a major commercial center due to its central location where communities in parts of Volta and eastern converge. The predominant "Abollo and One Mouth Thousand" is a common commodity been trade coupled with other small to medium size commercial entities.

The Asuogyaman District has an untapped tourism potential capable of transforming the district's economy and its overall contribution to national income when fully developed. The district is a seat of important national infrastructure and architectural landmarks which includes hydroelectric dam, the Suspension Bridge over the Volta at Adomi, inland port at Akosombo which facilitates transportation of goods and people to and from Akosombo and the northern regions of the country, the petroleum depot located at Adomi and Natural landscape for the development of tourism (Ghana Statistical Service, 2010).

\section{Method}

The study is a survey of Ada West and Asuogyaman District Assemblies to assess the implementation of the national policy on LED. The case study design made it possible to focus on the extent of implementation of the policy in the two District Assemblies. These two District Assemblies were purposively selected based on some resource endowment. The Ada West District was selected based on the endowment of salt deposits whiles the Asuogyaman was selected based on the presence of the Volta Lake. A questionnaire which was used to elicit primary data from key informants. Key assembly officials who are involved in the formulation and implementation of district plans such as the District Coordinating Directors (DCDs) and District Planning Officers (DPOs) were purposively selected as respondents. The study made use of qualitative data. Data analysis was done with the aid of the statistical software package SPSS.

\section{Result}

In order to facilitate the discussion, this chapter has been broken into sub sections. Initially, economic potentials of the two districts are explored. Thereafter, efforts being made by the assemblies towards the implementation of the LED policy are assesses. Finally, challenges faced in the implementation of the policy and the way forward from the perspective of the district assemblies are presented. Since the study was undertaken in two different districts, presentation of the findings has been structured to allow for easy comparison of situations as they exist the two districts.

\subsection{Economic Potentials and LED}

The study found that, the major natural resources found in the Ada West District were salt, sand and rocks, and vast arable land. The major economic activities undertaken by the people of the district included crop and animal farming, fishing, salt production, and trading, among others. Among these, the District Assembly had targeted salt production, farming and fishing for LED interventions.

In the Asuogyaman District, arable land, the Volta Lake, limestone and sand were the major natural resources found. The major economic activities undertaken by the people include crop farming, trading, tourism and craft, and fish farming. Here, the District Assembly had targeted support for youth in aquaculture, establishment of Tourism Information Centre and Museum, and revamping of abandoned State Farms for LED interventions. The Assembly had directly funded 15 youth to undergo training in aquaculture. The Assembly was also supporting some youth the making of bamboo products.

\subsection{LED Implementation Efforts}

It was found that both assemblies had not put in much effort specifically aimed at implementing the National LED Policy in their jurisdictions. They however, were undertaking some activities geared towards job creation for the people.

On the issue of knowledge of the existence of the National policy on LED, it was revealing to know that while the Asuogyaman District Assembly was aware of the policy and had thus incorporated it in their MTDP, the Ada West District was unaware about the existence of the policy.

On the setting up of District Economic Development Committees, it was found that both districts had not constituted such committees. The Assemblies cited lack of commitment and lack of knowledge for the Asuogyaman and Ada West Districts respectively as the main reasons for not constituting the EDCs.

It was also found that, both district assemblies had not undertaken any diagnostic analysis to acquire deeper knowledge of the local economy and the resources available for economic and social development. To this end, legal and regulatory frameworks to create the enabling environments for LED were absent. However, the assemblies had made efforts aimed at ensuring that the overall economic and social conditions of the districts were conducive to the creation of employment opportunities. The Asuogyaman District Assembly was charging low fees on businesses and this had attracted investors to the tourism sector of the district. On the part of the Ada West District Assembly, they had been ensuring the timely processing of documents and operated an open door policy to facilitate business activities.

On infrastructural support for LED, the Asuogyaman District Assembly had built market stores at Atimpoku; market sheds at various locations within the district and reshaped some feeder roads. These were geared towards facilitating the storage and sale of market products and opening up of farming communities for smooth transportation of farm products. The Ada West District Assembly, on its part, had built a training facility to train the youth and the business community on LED. The assembly had also provided a green house facility to farmers for the production of vegetables. 


\subsection{Challenges}

The study found the following to be the main challenges hindering the implementation of the National LED policy in the districts studied:

a). Lack of commitment on the part of the District Assemblies to implement the policy.

b). Inadequate financial resources to undertake activities relating to the implementation of the policy.

c). Lack of (adequate) knowledge about the National LED policy.

\section{Conclusions}

There is an increasing recognition that the quest to achieve national development goals could only happen when the goals are translated into actions at the sub-national levels and by active involvement of local actors. The Local Government Act of Ghana recognises District Assemblies as the agents responsible for the overall development of any district. Ghana's national LED policy formulated in 2013 has an overall goal of facilitating economic growth, employment and income generation in order to promote household welfare and alleviate poverty. Policies are important inputs to the economic development process of any territory. But policies, of themselves, cannot bring about the desired goals unless they are duly implemented; that is, the policy decisions carried out. In Ghana, experience has shown that many good policies formulated in the past did not get implemented. Also, the pace of implementation of many other policies has been terribly slow resulting in huge time lag between policy formulation and implementation.

This study thus investigated the extent of implementation of the national LED policy at the local level by District Assemblies using the Asuogyaman and Ada West District Assemblies as case study. The broad objective was to find out whether District Assemblies are delivering on their roles and responsibilities as provided by the National LED Policy.

The key finding of this study is that the District Assemblies studied had not put in much effort specifically aimed at implementing the National LED Policy in their jurisdictions. In the Asuogyaman District, it was found that, the Assembly had knowledge about the existence of the National LED policy and had thus incorporated it in their Medium Term Development Plan as required by the policy. The Ada West District on the other hand, was unaware about the existence of the LED policy and could therefore not incorporate same into their Medium Term Development Plan. However, in both districts, key activities that were expected to be undertaken in the first and second years of the plan implementation had not been carried out. These include:

a). establishment of DEDC

b). setting up of District LED Platform team

c). sensitization and awareness creation on LED

d). providing human, financial, and other resource support for LED implementation e). conducting baseline study on LED for future impact assessments

f). formulating local strategies for LED, and many others.

These notwithstanding, it was found also that, both assemblies are undertaking some activities that are geared towards job creation for their people. This is mainly in the area of infrastructure provision.

Challenges hindering the implementation of the LED Policy as cited by the Assemblies included lack of commitment to implement the policy, inadequate financial resources and lack of knowledge on the policy.

\section{Recommendations}

The findings of this study reveal that the District Assemblies have not put in adequate efforts to implement the National LED Policy. Subsequent to the findings therefore, the following recommendations are made:

a). The Ministry of Local Government and Rural Development should provide training to the assemblies on the policy emphasising on roles and responsibilities of the assemblies and the timelines for implementation.

b). District Assemblies should exercise greater commitment towards the implementation of the Policy

c). District Assemblies should enter into some partnership arrangements with private sector entities to mobilise financial and other logistical supports for successful implementation of the Policy.

\section{References}

[1] Rogerson, C. M. (2009). Strategic review of local economic development in South Africa: Final report submitted to Minister Sicelo Shiceka (dplg) Commissioned by the dplg and AHI.

[2] Bartik, T. J. (2003). Local economic development policies. Upjohn Institute Staff Working Paper 03-91.

[3] Cardiff consensus for local economic development (2011). Energising local economies: Partnerships for prosperous communities. $\quad$ Retrieved from http://www.clgf.org.uk/userfiles/1/files/Cardiff\%20consensus $\% 202011 \% 20$ final.pdf

[4] Blakely, E. J. \& Bradshaw, T. K. (2002). Planning local economic development: Theory and practice. London: Sage Publications.

[5] Baker, R., Michaels, R. \& Preston, E. (1975). Public policy development: Linking the technical and political process. New York: John Wiley.

[6] Mensah, J. K., Bawole, J. N. \& Ahenkan, A. (2013). Local economic development initiatives in Ghana: The challenges and the way forward. Journal of Public Administration and Governance, 3(2).

[7] Republic of Ghana (1993). Local Government Act 462.

[8] World Bank (2001) Local economic development: Quick reference, Urban Development Division, The World Bank, Washington DC. 
[9] Helmsing, A. H. J. \& Egziabher, T. G. (2005). Local economic development in Africa: Introducing the issues, in T.G. Egziabher and A. H. J. Helmsing (eds.), Local economic development in Africa: Enterprises, communities and local development. Maastricht: Shaker Publishing BV.

[10] ILO (2006). A local economic development manual for China, ILO, Geneva.

[11] Tello, M. D. (2010). From national to local economic development: Theoretical issues. Cepal Review 102.

[12] Koma, S. B. (2014). Developmental local government with reference to the implementation of local economic development policy. Unpublished doctoral thesis, University of Pretoria, Pretoria, South Africa.

[13] Rodriguez-Pose, A., \& Tijmstra, S. (2009). On the emergence and significance of local economic development strategies. CAF Working Paper, CAF. 7.
[14] [Akudugu, J. A. \& Laube, W. (2013). Implementing local economic development in Ghana: Multiple actors and rationalities. ZEF Working Paper 113.

[15] Catenacci, Bruno Edt. (December 2003). Local economic development agencies. Retrieved from http://www.yorku.ca/ishd/adel.ENG.pdf.

[16] Republic of Ghana (1992). Constitution of the Republic of Ghana.

[17] Ministry of Local Government and Rural Development (2013). National local economic development policy.

[18] Republic of Ghana (2010). National Decentralisation Policy.

[19] Ghana Statistical Service (2014). 2010 population and housing census district analytical report: Ada West District.

[20] Ghana Statistical Service (2014). 2010 population and housing census district analytical report: Asuogyaman District. 